\title{
GENERALIDADES SOBRE FOTOGRAFÍA Y MEMORIA DE LAS VÍCTIMAS DEL CONFLICTO ARMADO COLOMBIANO A PARTIR DE TRES EJEMPLOS RECIENTES. REFLEXIONES SOBRE TRAGEDIAS COMPARTIDAS Y RESISTENCIAS
}

\author{
Natalia Vanessa Ramírez Peña ${ }^{1}$
}

\section{Introducción}

Desde los cimientos que han sostenido su desenvolvimiento como país, Colombia ha experimentado diversos tipos de violencias internas que la han llevado a fijar dentro de sus imaginarios sociales, la presencia constante de conceptos como conflicto o guerra, así como también los de recuperación y paz, este último, se había vuelto un objetivo que en ocasiones, en medio de las vigentes dinámicas políticas, insurgentes y nacionales, parecía lejano de alcanzar. Solo, luego de dar inicio formal al proceso de paz, gracias a la firma en 2016 los acuerdos que ponían fin definitivo al fuego entre el estado y las FARC, una guerrilla con más de cincuenta años de existencia, aquel objetivo se volvió algo palpable; eventualmente, comenzaron a ejecutarse los primeros pasos para una economía más equilibrada, un territorio rural más estable y claro, menos víctimas asociadas a dicho fenómeno.

Ese concepto, o mejor, esta aproximación a un entorno pacífico, aumentó e inclinó (pues ya previamente era tema de discusiones e investigaciones variadas) el interés de académicos de todas las áreas del conocimiento, hacia estudios ligados a las afectaciones e impactos del conflicto interno sobre, por ejemplo, el ecosistema, la geografía, las finanzas, el urbanismo de las regiones... básicamente porque la presencia del ejército, guerrillas, paramilitares y todo tipo de grupos insurrectos, dificultó el acceso seguro de la población externa a sus zonas de concentración, tornándolas desconocidas en varios aspectos para las ciencias en general. Ciertamente, los estudios sobre arte y memoria no han escapado a los mencionados intereses, en primer lugar porque hacer del conflicto un

\footnotetext{
${ }^{1}$ Universidade Federal de Pelotas. Email: nataliavarape@gmail.com ORCID id: https://orcid.org/0000-0001-6364-4127
} 
tema o inspiración para la creación de determinada expresión artística, por décadas a lo largo y ancho del país, merece análisis profundos ya que involucran referencias específicas e incluso, emociones compartidas y otras tantas divididas, en segundo lugar, porque pensar en memoria implica pensar en las marcas del pasado a partir de las percepciones del presente, teniendo en cuenta los tiempos, las cifras, los actores y las razones de la violencia en Colombia, y en particular, las del conflicto interno armado preponderante en las más de cincuenta décadas recientes, es algo vital para identificar lo que lo provocó, lo que ocasionó y su prevención a futuro.

En este orden de ideas, quiero concentrarme en las siguientes páginas en el cómo la labor fotográfica de algunos artistas colombianos, ha logrado presentar emociones propias de un tejido social afectado por las acciones de los actores armados, que difícilmente han concebido a quienes viven o padecen de manera directa o indirecta las consecuencias, como víctimas, y que bajo el marco del proceso de paz anteriormente señalado han ganado un poco más de presencia y participación. Ya que las imágenes a exponer nacen de la experiencia de la violencia en Colombia, se espera destacar el potencial de memoria inherente a este tipo de producciones ligadas al contexto, la cultura y a la realidad reciente del país.

\section{Más allá de la palabra no dicha. Transversalidades entre imágenes y emociones}

Sin duda, las tragedias vivenciadas en Colombia a lo largo de los casi sesenta últimos años de conflicto, han permitido el registro de imágenes compuestas por rostros, situaciones reales, padecimientos, a veces trayendo como resultado evocaciones de sentimientos como la desesperanza, que dan cuenta del modo en que esta sociedad se ha estado gastando, la objetividad de la fotografía de tendencia periodística y documental, vienen materializando a cabalidad tal labor hace décadas, dentro y fuera de la prensa nacional.

No en tanto, para de ahondar en la emotividad de las imágenes fotográficas, prefiero remitirme a aquellas que cuestan explicar, porque irrumpen en nuestras sensaciones internas, o mejor, revelan como lo han sido las de otros. Imágenes cargadas de 
conmociones que transitan entre los extremos de los sentimientos que nos hace humanos, y las memorias inscritas en el recuerdo de sus detonantes; ellas, forman parte de eso que los pobre mortales se inventan para registrar sus estremecimientos (de deseo o de temor) y la manera como ellos también se consumen. (Huberman, 2012: 17). Los artistas del cono sur, se han caracterizado por impulsar la necesidad de hacer visible lo que nos duele o nos ha dolido por largos periodos de tiempo, por supuesto también las alegrías o lo que nos enorgullece personal o grupalmente, en ese caso, en su interior, todas son preliminarmente, cuestiones plasmadas sin fecha de caducidad, en la medida en que han sobrevivido al olvido, de alguna manera porque siguen presentándose en la cotidianamente de la actualidad. Didi Huberman reflexiona casi poéticamente sobre la importancia de este tipo de objetos (imágenes), puntualizando:

Para cada uno de nosotros, todos forman en conjunto un tesoro o una tumba de la memoria, no importa si ese tesoro es un siempre copo o si esa memoria está trazada sobre la arena poco antes de que una ola la disuelva. Sabemos perfectamente que toda memoria está siempre amenazada de olvido, cada tesoro amenazado de pillaje, cada tumba amenazada de profanación. (2012: 17)

Ninguna manifestación de arte es inocente, la fotografía de los artistas colombianos mucho menos, la naturaleza sensible de su contenido la ha convertido en símbolo de resistencia y de la "profanación" aludiendo a Huberman, dado a que no busca a penas referirse a alguna barbarie, masacre o arremetida contra algún derecho humano sino más bien a lo padecido por las víctimas, en otras palabras, busca retomar lo que las cifras y los formalismos, que la historia como campo científico aplica en sus indagaciones, no podrían acaparar al no ser parte de sus parámetros. El recuerdo de la cruel muerte de un pariente, la extorsión imparable, el desplazamiento forzado de una comunidad, la pérdida de un hijo por actos guerreristas o por el narcotráfico, entre otros eventos trágicos, desde luego, acarrean angustias y tristezas complejas de describir en palabras, es ahí donde entra la imagen externa a suscitar la lectura de estos y otros tantos padecimientos en ocasiones personales, en ocasiones colectivos.

De hecho, los registros fotográficos tienen la facilidad de poner ante el observador, instantes pasados todavía vivos gracias a las emociones de las que dispone y con las cuales es posible sentirse identificado, en el asunto convocado, mujeres y hombres 
víctimas del conflicto interno colombiano (incluyendo la mayoría de veces a los propios artistas), que convergen muchas veces no a raíz de su localización, etnia, género o clase social, sino por el hecho de haber tenido experiencias iguales o semejantes, la posibilidad de rememorarlos y encontrar su vínculo con lo vigente. Son numerosas las emociones nacidas de un mismo acontecimiento o vivencia de índole traumática, escuchar sus voces conlleva a inquirir en sus orígenes, en las relaciones entre grupos involucrados y a su vez en los relatos que escapan de la uniformidad de las consolidadas como historias e identidades nacionales.

\section{Las memorias trágicas de las víctimas. Historias afuera de la sombra}

Trabajos fotográficos como los de los colombianos Doris Salcedo o los de Carlos Saavedra (retomado más adelante), son fundamentados desde lo memorable, o sea, desde lo que merece ser conservado en la memoria; basados en el pensamiento de Joël Candau, a través Uma interpretação, uma leitura da historia das tragédias (2014: 151), en esencia, sus imágenes reafirman la idea de buscar la paz sin dejar a un lado los recuerdos de sufrimientos que si bien su reparación total es casi improbable, sus propietarios son sinónimo de valentía y de disputa contra la impunidad, en un intento por comunicarle a los demás lo doloroso que es pasar por una tragedia que no regresará a alguien o algo específico.

Las obras con ese tinte nostálgico no están adscritas del todo a lo material, su accionar se da en las peculiaridades y dimensiones de un pasado específico únicamente evocado a partir de la connotación de símbolos, por lo que los poetas, músicos, pintores, escultores, etc, inspirados en los dramas del fenómeno conflictivo colombiano han sabido escavar en medio de lo no dicho con el propósito de fortalecer su no omisión en las ideologías de los comprendidos, en este sentido, dar significado al impacto de hechos muchas veces ignorados, muchas veces invisibilizados por discursos interesados en hacer ver homogénea la memoria social del mismo, se convirtió en uno de los fines de su creatividad. Candau (2014: 168) afirma que los grupos minoritarios de cualquier sociedad, ejecutan esfuerzos constantes pasa conferirse un pasado propio partiendo de reformas 
aplicadas a modelos impuestos por grupos dominantes, a modo de ejemplo resalta cómo los afrodescendientes en Estados Unidos han acudido a la lectura de imágenes de otros grupos también afrodescendientes y/o minoritarios del mundo (nivelando lo creado y lo reproducido), para consolidar una identidad específica y no una con recuerdos de "afros".

El contribuir con la construcción un pasado sujeto al sufrimiento de los más perjudicados, siguiendo los lenguajes del arte es "revelar ciertos códigos de la sociedad en que están inmersos y mostrar que están lejos de realidades lineales y previsibles" (Pini, 2009: 47), en un país en donde el mismo estado es responsable de ataques a la población marginada e inocente, cuestionar la historia oficial es un compromiso siempre necesario. Aunque existen muchos artistas que valdrían la pena citar en las próximas líneas debido a la profundidad reflexiva de su ejercicio creativo, me centraré en tres trabajos fotográficos cuyo mensaje, en cuanto va desplegando las emociones de ciertos damnificados, ejerce un papel de denuncia social.

En primer lugar está la serie fotográfica Réquiem $N N$ (Fotografías 1 y 2) de Juan Manuel Echavarría, en la que se relata la suerte de los cadáveres de posibles víctimas de guerrillas y/o paramilitares que naufragando por el rio Magdalena llegaban hasta Puerto Berrío, Antioquia, territorio de alto interés de los grupos armados ilegales por su cercanía con zonas estratégicas del país. Desconociendo completamente la identidad de los cuerpos, los habitantes aledaños los trasladaban al cementerio con el propósito de que tuvieran sepulcro y posteriormente, a cambio de la protección, cuidado de la tumba, visitas, flores y oraciones, las almas de quienes encontraron (en ocasiones bautizados bajo las iniciales NN, en otras, con nombres concedidos por integrantes de la comunidad), cuidaran de sus familias en general. Sin embargo, existe una razón importante motivadora del acogimiento dado a tales individuos; el hecho de que representan los parientes y amigos que han desaparecido o han muerto a causa de la violencia acontecida en el municipio. 


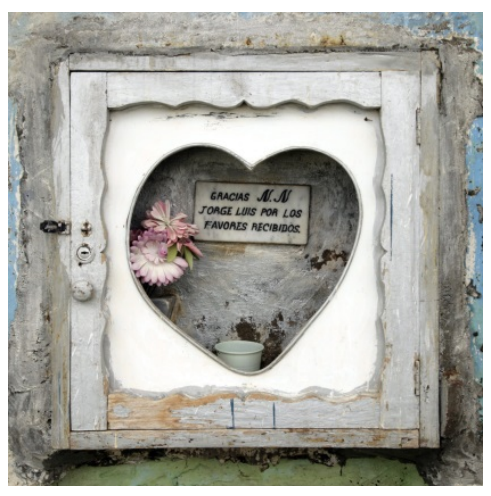

Fig 1: Juan Manuel Echavarría, Requiem NN (2006-2013), Fotografía Fuente: Disponible en: https://www.fotografiacolombiana.com/rios-silenciosjuan-manuel-echavarrial

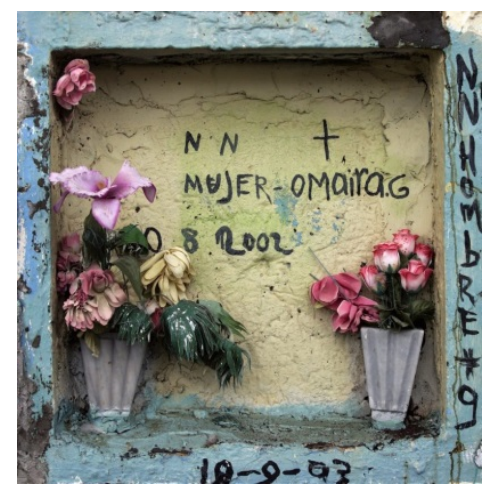

Fig 2: Juan Manuel Echavarría, Requiem NN (2006-2013), Fotografía Fuente: Disponible en: https://www.viceversa-mag.com/juan-manuel-echavarria-me-interesanlas-huellas-que-deja-la-guerra/

Y es que la situación en mención, de carácter ritualista o mística, es muestra de las prácticas colectivas surgidas de ambientes en los que predominan las fronteras invisibles, el mando de insurgentes, la economía atada a lo producido ilícitamente y la ausencia del estado. La incursión de dichas prácticas transformó la memoria colectiva de los residentes de Puerto Berrio, e igualmente, volvió a esos seres anónimos nuevos miembros de la comunidad, como si dignificarlos bridase la oportunidad que no les dio la vida para dar entierro digno a conocidos y familiares asesinados o desaparecidos por la violencia del municipio y a la larga, del país. Es un doble duelo, porque se recuerda a quien está ausente mientras paralelamente, se le despide a un ser presente adoptado como propio. 
El trabajo de Echavarría refleja las formas asumidas por comunidades periféricas colombianas a la hora de lidiar con la muerte, pues aunque pareciera inherente a sus cotidianidades, humanizar lo que a veces solamente es visto como un aumento en las cifras de las tragedias causadas por el conflicto, hace un tanto más llevadera la vida allí, donde la realidad de los grupos no está en sincronía con la llevada en los centros ni se asemeja del todo a la expuesta por los medios de comunicación relevantes. En vista de que [...] O pertencimento de cada individuo a uma pluralidade de grupos torna impossível a construção de uma memoria unificada e provoca uma fragmentação de memorias. (Candau, 2014: 172), la segunda propuesta se constituye en función de las marcas internas provocadas por las situaciones que volvieron a las memorias de las víctimas, vestigios de un pasado permeado por resiliencia, ausencia, dolor, silencio y pérdida.

Hablar de marcas internas, es aludir a lo tácito, a lo que el cuerpo no consigue transmitir del todo, y si lo lograse, sería someramente porque las emociones o los sentimientos no encajan en marcos conceptuales fijos. La serie fotográfica La necesidad de las ruinas (2016) (Fotografía 3) del artista bogotano Francisco José Mojica desea ir más allá de las referencias realistas del sufrimiento humano, es decir, su obra prescinde de la dimensión objetiva con miras a restituir lo abolido por el pasar del tiempo, cuya lucha contra la negligencia de los entes responsables ha conducido a constituir el presente de sus poseedores, de manera que genera la impresión de estar frente a monumentos, a homenajes dedicados a emociones y sentimientos desoladores, vividos introspectivamente por miles de personas en el contexto colombiano.

Siendo ganador del XII Premio nacional Colombo Suizo de fotografía, Mojica explica la intención de las imágenes diciendo: "Se trata de utilizar los cuerpos de polillas que han perdido sus características físicas por la acción de los elementos, a manera de metáfora para hablar del olvido, de la memoria, y abordar el tema del tejido social, de los derechos humanos." El proceso técnico aplicado a los pequeños cuerpos de las polillas (ampliados por el lente de la cámara) les otorgó un delicado aspecto entre tonalidades blanquecinas y grisáceas, que pareciera, complementara delicadeza con la cual son simbolizados los recuerdos trágicos e indelebles, derivados de la violencia interna del país, que espera, el observador les asocie. 


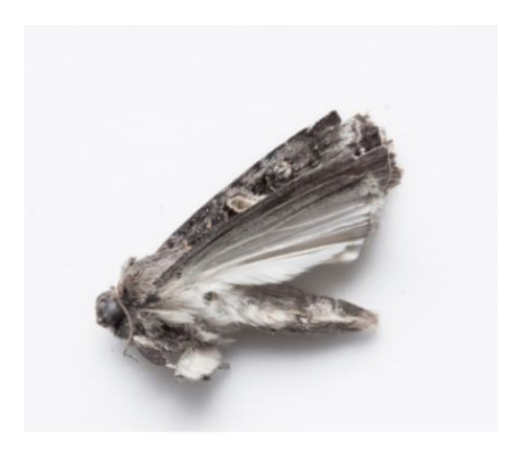

Fig 3: Francisco José Mojica. La necesidad de las ruinas (2016), Fotografía Fuente: Disponible en: http://www.fotografiacolombiana.com/la-necesidad-de-las-ruinasfrancisco-mojica-xii-premio-nacional-colombo-suizo-de-fotografial

En las fotografías de Echavarría observamos actos explícitos surgidos de la iniciativa de lidiar con las crudas vivencias resultantes de la perdida un ser querido en zonas de guerra, en las de Mojica en cambio, contemplamos alegóricamente algunos aspectos sentimentales que no podrán ser reparados, pues su huella queda en el alma, en el corazón... a través de penas, traumas, heridas invisibles. La búsqueda de interpretaciones fuera de lo tradicional se vale también de creaciones disímiles a los formatos tradicionales, en efecto, según la profesora Ivonne Pini:

Existe la necesidad de resquebrajar ciertos modelos de identidad demasiado globalizadores, no sólo para mostrar la complejidad del arte latinoamericano, sino para volver a valorar las culturas que lo integran. La ruptura de modelos hegemónicos supone investigar en el pasado, evitar las definiciones reduccionistas y adoptar la diversidad como postulado. (2009: 49)

Se trata de llevar a cabo la acción creativa, asignándole códigos y/o materiales poco convencionales que prontamente le insinúen al espectador que está a punto de presenciar una obra y un contenido motivados por entornos socioculturales complejos, merecedores entonces de cierta forma y contenido particular, casi únicos, así como lo son todos los conflictos.

El tercer registro fotográfico a destacar aquí le concierne a las fotografías de la exposición Madres Terra (2018), conformada por quince retratos de madres que en 2008 perdieron sus hijos a causa de los asesinatos cometidos por las fuerzas militares a personas 
del común, para hacerlos pasar como miembros de grupos insurrectos y demostrarle al gobierno, por supuesto al país también, su efectividad en la contienda armada. El fotógrafo colombiano Carlos Saavedra similarmente a Echavarría, con la finalidad de presentar algunos de los rostros víctimas de actos de guerra en el país y asimismo, recordar a todas las vidas de inocentes que se ha llevado, apela al acto del entierro para poner en diálogo la vida y la muerte.

En su propuesta (Fotografías 4 y 5), Saavedra optó por enterrar a estas mujeres, al punto de dejar descubierto algunas partes del cuerpo como hombros, brazos, manos; no obstante, sus rostros están descubiertos en todas, dejando entrever rasgos naturales (arrugas, marcas, pecas, etc.), sus cabellos y lo más conmovedor, gestos llenos de una y mil sensaciones enlazadas fuertemente con su vulnerabilidad. El formato blanco y negro nos pone a pensar en los sentimientos allí latentes, la tierra oscura junto con sus rocas y raíces, cubre a las mujeres generando una escena de doble maternidad, de doble origen. "Las madres de Soacha", como también son conocidas las mujeres retratadas, hoy en día continúan denunciando la no resolución de los delitos cometidos por el estado hacia ellas y sus familias, viviendo la frustración y la rabia por las injusticias vividas y claro, intentando recordar a diario los hijos, hermanos, esposos, padres arrebatados mientras esperan el momento en que por fin sus relatos sean oídos y legitimados por las fuerzas hegemónicas de la nación.

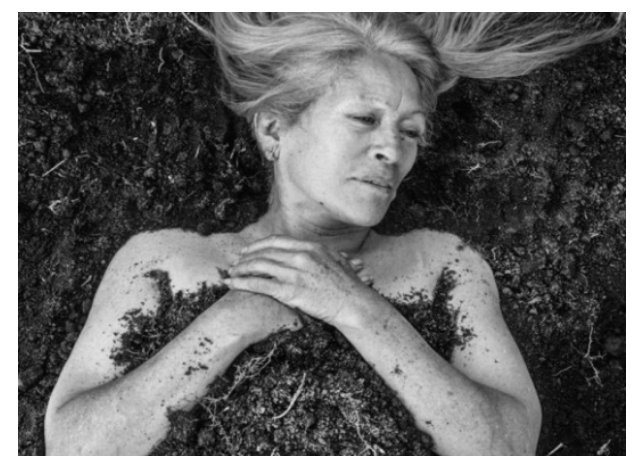

Fig 4: Carlos Saavedra. Serie Madres Terra (2018), Fotografía Fuente: Disponible en: https://www.vice.com/es co/article/wijkyw/fotografia-entierro-madres-de-soachasuturar-falsos-positivos 


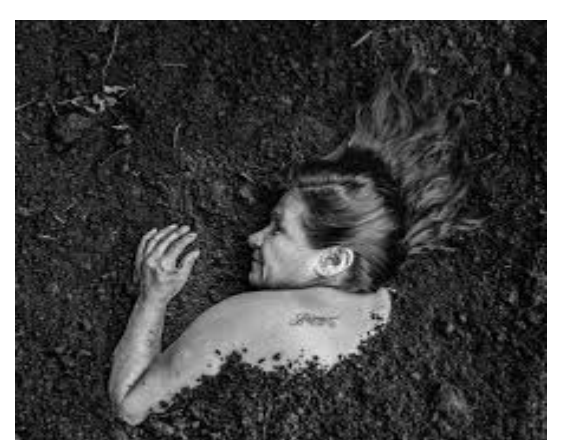

Fig 5: Carlos Saavedra. Serie Madres Terra (2018), Fotografía

Fuente: Disponible en: https://www.vice.com/es co/article/wjikyw/fotografia-entierro-madres-de-soachasuturar-falsos-positivos

Las imágenes de Saavedra procuran reflejar acontecimientos verídicos no contados y sin ningún aval. Miles de víctimas guardan dentro de sí o dentro de sus colectivos íntimos, los recuerdos de sucesos olvidados por las mayorías, contados con irregularidades e incluso desconocidos por quienes tienen el poder de regular o escribir la historia que nos identifique a todos, estas son las situaciones que, de acuerdo con el fotógrafo, el arte originado en contextos conflictivos, debe cuestionar debido a la capacidad que tiene de extraer lo subjetivo en la realidad concreta. En sus palabras:

\begin{abstract}
"Las víctimas de las violencias múltiples en Colombia no tienen, no se les han dado tampoco, muchas herramientas para sanar y hacer su duelo. Lo mejor a lo que pueden aspirar es, quizá, una casa, un poco de dinero y ya está. Pero lo más difícil, lo psicológico, suele quedar de lado. El mundo entero suele no concentrarse en la psicología después de una guerra. Y sin duda aquí el arte se ha convertido en una gran herramienta para que las víctimas hablen, para que las víctimas enfrenten su duelo. $\mathrm{Y}$ enfrentar a alguien frente a una fotografía suya o a una pintura, verse a uno mismo, algo hace en uno. Contar la historia de uno a otra persona, así sea un fotógrafo, también hace algo en uno".
\end{abstract}

La idea no es contar verdades más si exaltar los dolores no sanados y atender a versiones alternativas de los hechos cuestionados. En el marco de un proceso de paz, o de un período de pos conflicto, son actividades a realizar si se quiere alcanzar una reparación equilibrada, en concomitancia con las grupos marginados (hombres, mujeres y niños indígenas, campesinos, comunidades periféricas, afrodescendientes...), es decir, aquellas personas que fueron silenciadas pero que poseen en definitiva, el mayor número de afectados y por los cuales es vital la construcción de un pasado común, que involucre el impacto de los actos bélicos realizados por estado, guerrillas, paramilitares, narcotraficantes, criminales diversos, sobre ellos y sobre las comunidades implicadas. 


\section{Apreciaciones Finales}

Como se vio, encontramos en la potencia de la fotografía el camino visual para traer a flote el alma, el corazón y el espíritu de un sinnúmero de colombianos aquejados por la violencia, su independencia del objeto o del ser humano plasmado en el papel la vuelve rápida y efectiva a la hora de comunicar un sentimiento o un conjunto de estos, provenientes del recuerdo de un episodio o de las emociones vividas. El trio de fotógrafos colombianos, de la mano de cada uno de sus proyectos documentan las historias no legitimadas de los que han vivido además de los ataques y los contraataques guerreristas, la amnesia ejercida por el resto ciudadanía y los responsables, sobre los mismos.

Los registros de las tumbas de Manuel Echavarría, nos indican que en los lugares confinados y más aquejados hay prácticas repletas de valor espiritual con las que se rememora los seres queridos conocidos y ausentes, por medio de la presencia de los seres apropiados como queridos-desconocidos, los de Francisco Mojica nos brindan indicios del estado emocional y de la situación interna de, por ejemplo, los ejecutores de esas prácticas; ya en las imágenes de Carlos Saavedra, contemplamos en sí, el rostro de unas víctimas que bien podrían representar a las de las dos anteriores obras. Finalmente, veo entonces una tarea espontáneamente mancomunada en los artistas, cada uno, partiendo de su creatividad y manera de hacer las cosas, tratan de traer al presente las voces, los rostros, las secuelas y las narraciones "Subterráneas", parafraseando a Michael Pollak, en cuanto refuerzan la necesidad de una reivindicación hacia ellos por parte de los sectores dominantes, y la otra sección de la sociedad que dichos sectores han convencido de mantenerlos al margen de lo avalado por fuentes oficiales (las respaldadas por gobierno, incrédulos y opositores).

El producir y estudiar las manifestaciones artísticas de Colombia será siempre un evento imbricado con la memoria, los virtuosos de todos los campos del arte, enfocados en crear con base a temáticas del conflicto armado, hacen un llamado a la entereza e inscriben en escenarios públicos lo que está o puede estar amenazado por el olvido. Al igual que las maneras de contar o reconstruir algo pueden ser variadas, las memorias también lo son, de ahí que la actividad artística (grupal o autónoma) aludida, tenga tanta articulación con el contexto e intente dignificar a quienes han callado física y/o metafóricamente, esto es un asunto que aún no acaba, pues todavía le apunta a la 
consolidación de la paz de adentro hacia afuera de los territorios y a la no repetición de tantas tragedias.

\section{REFERENCIAS}

CANDAU, Joel. Memória e Identidade. São Paulo: Contexto, 2014

CRUZ, Fernando. Francisco Mojica, Premio Nacional Colombo Suizo de Fotografía-Una mirada desde el presente. 2019. Disponível em: https://www.youtube.com/watch?v=Zh5E8MfWwfU <Acesso em: 05 nov. 2019>

Huberman, Didi. Arde la imagen. Oaxaca: Ediciones Ve S.A de C.V, 2012

PINI, Ivonne. Fragmentos de Memoria. Los artistas latinoamericanos piensan el pasado. Bogotá: Editorial: Universidad Nacional de Colombia (Sede Bogotá), 2001

SÁNCHEZ, Felipe. Este fotógrafo enterró a las madres de Soacha para suturar sus heridas. Con la serie 'Madres Terra', el fotógrafo cartagenero Carlos Saavedra ganó el premio 'Everyday Heroine Award Grant' y estará exponiendo en Londres en octubre, Bogotá, 30 Agosto 2017. Disponível em: <https://www.vice.com/es co/article/wijkyw/fotografiaentierro-madres-de-soacha-suturar-falsos-positivos>. Acesso em: 08 nov 2019

Recebido: $05 / 03 / 2020$

Aprovado: $08 / 12 / 2020$ 